\title{
EVOLUÇÃO DO PROCESSO EROSIVO NA MARGEM DIREITA DO RIO SÃO FRANCISCO (PERÍMETRO IRRIGADO COTINGUIBA/PINDOBA - SE) $)^{(\mathbf{1})}$
}

\author{
A. P. B. CASADO(2), F. S. R. HOLANDA(3), \\ F. A. G. ARAÚJ O FILHO(4) \& P. YAGUIU(4)
}

\begin{abstract}
RESUMO
A erosão das margens de um rio causa a destruição das áreas ribeirinhas, contribui para a degradação de grandes áreas e produz efeitos catastróficos para o ambiente, ocorrendo a ruptura do equilíbrio ambiental. Este trabalho teve como objetivo quantificar as taxas de recuo da margem direita do rio São F rancisco em três seções localizadas no Perímetro Irrigado Cotingui ba/Pindoba - Baixo São Francisco Sergi pano - no período de fevereiro de 1999 a julho de 2000 e estudar as possíveis causas do processo. Para quantificar as taxas erosivas, foram utilizados os métodos dos pinos e das estacas e para descrever o processo erosivo foi utilizado o método das perfilagens sucessivas. As taxas anuais de erosão (recuo da margem), obtidas nas três seções da margem estudada, foram de $8,30 \mathrm{~m}$ na seção $A ; 47,30 \mathrm{~m}$ na seção $B$ e $4,45 \mathrm{~m}$ na seção $C$. A variação das taxas de erosão foi influenciada, principalmente, pela composição granulométrica das camadas que compõem a face da margem e altura do barranco, como também pela associação dos dados climáticos e hidrológicos - velocidade do vento, amplitude mensal da cota, cota máxima mensal e velocidade do fluxo próxima à margem.
\end{abstract}

Termos de indexação: erosão marginal, degradação ambiental, impacto ambiental.

(1) Recebido para publicação em dezembro de 2000 e aprovado em agosto de 2001.

(2) Mestre em Desenvolvimento e Meio Ambiente pela Universidade Federal de Sergipe - UFS. Alameda A, 155/1102, Ed. Cactus, CEP 49025-000 Aracajú (SE). E-mail: apbcasado@bol.com.br

(3) Professor do Departamento de Engenharia Agronômica, UFS. E-mail: fholanda@infonet.com.br

(4) Graduando em Engenharia Agronômica, UFS. Bolsista do PIBIC. 


\title{
SUMMARY: BANK EROSION EVOLUTION IN SÃO FRANCISCO RIVER (COTINGUIBA/ PINDOBA - SE) IRRIGATED AREA
}

\begin{abstract}
Bank erosion causes destruction of thearea near theriver, contributes to thedegradation of l argeareas and causes catastrophic effects on theenvironment as well as a rupture of the environmental balance. This research was devel oped to quantify bank erosion rates, from February 1999 to J uly 2000 and to study the possible causes of the process. For the San Francisco River thepins and pegs methods wereused to measure the erosiverate, with the successive profiling being used to describe the erosive process. The annual rates of bank erosion obtai ned in thethresections were $8.30 \mathrm{~m}$ (section A); $47.30 \mathrm{~m}$ (section B) and $4.45 \mathrm{~m}$ (section C). As for erosion variation, the association of climatic and hydrological data wind speed, monthly amplitude quota, maximum monthly quota and the speed flux near the edge - were the factors that most influenced the erosi ve process. Erosion variation was al so influenced by the soil texture, forming the edge and height of the palisade.
\end{abstract}

Index terms: bank erosion, environmental degradation, environmental impact.

\section{INTRODUÇÃO}

A erosão marginal, ou erosão das margens de um rio, como componente da erosão fluvial, éaquela que destrói as margens dos rios, desempenhando importante papel no aumento da largura do canal. Este tipo de erosão contribui significativamente no incremento da carga de fundo dos rios e provoca destruição progressiva da área marginal, desval orizando os terrenos ribeirinhos e limitando o seu uso adequado (Thorne e Tovey, 1981). A ocorrência desse processo, segundo Fernandez (1990), é devida à remoção dos materiais do barranco pela ação fluvial (correntes, ondas) ou pela precipitação pluviométrica. A denominação de barranco é usada em quase todo o Brasil para as margens de um rio que apresentam certa altura. Essa faixa de terras emersas ou firmes junto às águas de um rio - várzeas - é parte integrante do vale fluvial, e as pequenas formas de rel evo geradas por processos geomórficos atuais nas margens enquadram-se no sexto taxon da classificação de Ross (1992).

Segundo Hooke (1979), a evolução do processo de erosão marginal érápida, comparada à de outros processos geomorfológicos. I sso acentua a importância do estudo na interpretação da mudança da paisagem, bem como o conhecimento das taxas de erosão marginal, que são de grande valor na investigação dos efeitos das atividades humanas na mudança da forma do canal e uma predição, em pouco tempo, da er osão e o planejamento para o seu controle. Além disso, de acordo com Casado (2000), a quantificação do processo erosivo constitui uma ferramenta indispensável à realização de um diagnóstico de problemas ambientais, além deservir desubsídio para a el aboração de políticas que visem resolver ou mesmo minimizar tais problemas.

De acordo com Fernandez (1995), a atuação dos principais agentes er osivos que comandam a erosão marginal ainda gera dúvidas. As diferentes conclusões a que vários cientistas chegaram a respeito dos fatores que controlam a erosão marginal são decorrentes das diversas condições pedológicas, hidrológicas e climáticas das áreas estudadas.

Segundo Hooke (1980, p.143), existem três principais fontes de informações utilizadas no estudo da velocidade de recuo das margens fluviais:

\footnotetext{
“(...) medições diretas no campo (Wolman, 1959; Twidale, 1964; Knighton, 1973) para um período de um a 10 anos; comparação de mapas antigos e fotografias aéreas em diferentes datas (Carey, 1969; Lewin, 1972; Mosley, 1975) para um período de 10 a 200 anos; e a utilização de evidências biológicas e sedimentares datáveis (Everitt, 1968; Hickin \& Nanson, 1975) para um período de 30 a 500 anos."
}

Dentre os métodos de quantificação da erosão marginal, usando medições diretas no campo, destacam-se o método dos pinos e o método das estacas.

Os objetivos deste trabal ho foram quantificar as taxas de recuo da margem direita do rio São Francisco, no trecho que compreende o Perímetro I rrigado Cotinguiba/P indoba, no período de janeiro de 1999 a julho de 2000, eestudar as possíveis causas desse processo. 


\section{MATERIAL E MÉTODOS}

\section{Caracterização da área de estudo}

A área de estudo compreende um trecho da margem direita do rio São F rancisco, com extensão de 11 km, localizada na área do Perímetro I rrigado Cotinguiba/Pindoba, a aproximadamente $75 \mathrm{~km}$ da sua foz, que abrange terras dos municípios de Propriá, Neópolis e J apoatã no estado de Sergipe (Figura 1).
Geol ogicamente, a área estudada está situada na porção oeste da Bacia Sedimentar de Sergipe. Nesta região, o contato entre rochas sedi mentares da Bacia e rochas plutônicas e metassedimentares da Faixa deDobramentos dá-seaolongo da Fal ha de Propriá, de direção nordeste-sudoeste. Recobrindo a unidade da Bacia Sedimentar, ocorrem formações superficiais, cenozóicas, constituídas pelos sedimentos continentais terciários do Grupo Barreiras e pelos sedimentos quaternários - pleistocênicos e holocê nicos.

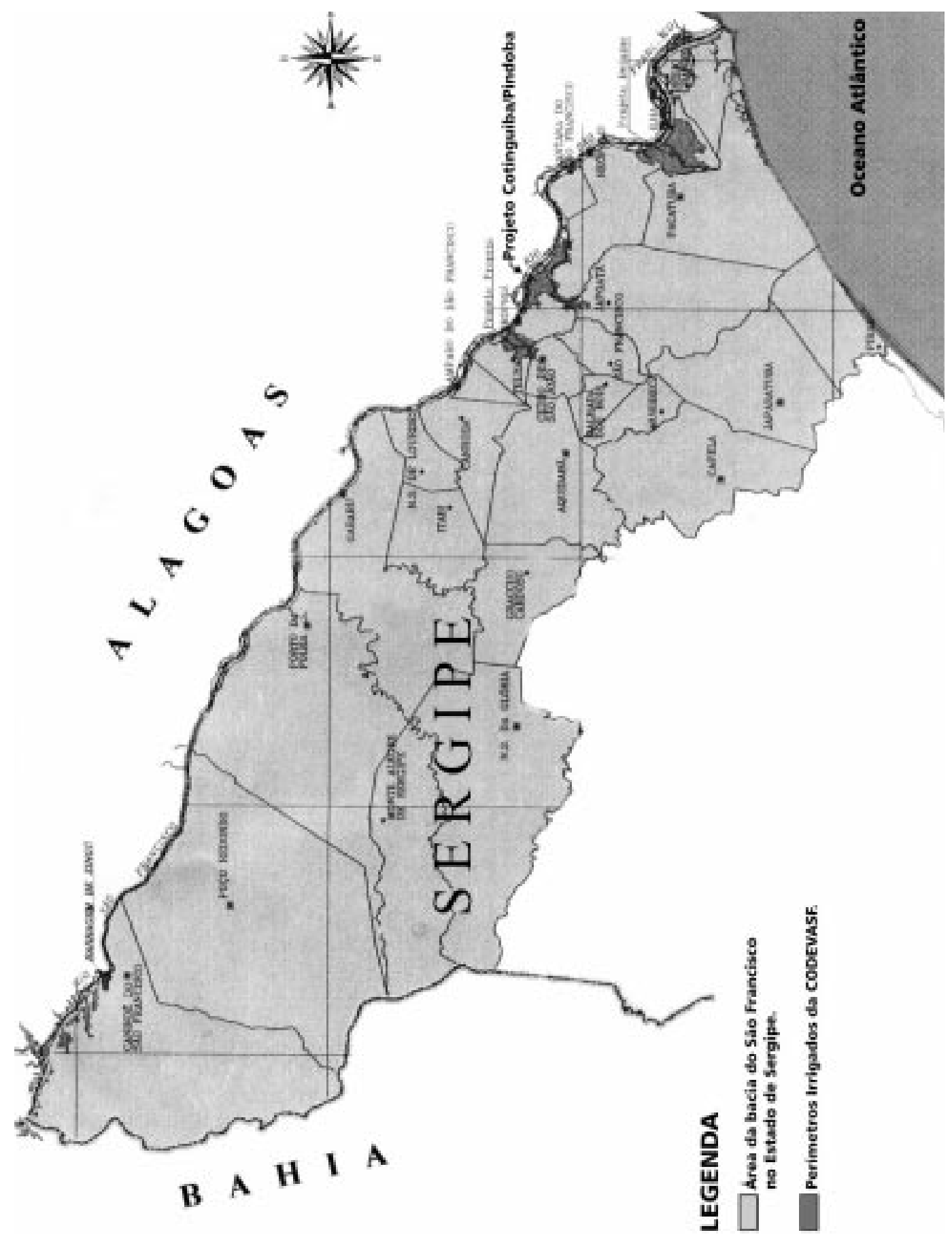

Figura 1. Localização do perímetro irrigado Cotingui ba/Pindoba. 
As unidades estratigráficas que formam o substrato da área do Perímetrol rrigado Cotinguiba/ Pindoba são: a Formação Serraria do Grupo Perucaba e as Formações Penedo e Barra de I tiúba do Grupo Coruripe, ambas do Cretácio I nferior.

Geomorfol ogicamente, a área de estudo local izase na planície fluvial do rio São Francisco, que compreendea faixa do vale composta por sedimentos aluviais que bordejam os cursos de água e periodicamente é inundada pelas águas de transbordamento (Fontes, 1999).

Segundo Holanda (2000), predominam na área os N eossol os Flúvicos. Essetipo de solo desenvolvese em planícies aluvionais, em depósitos recentes de origem fluvial. São solos que apresentam propriedades que podem variar consideravelmente a curta distância vertical e, ou, horizontal (Oliveira et al., 1992).

Em termos climáticos, predomina na região o dima quente do tipo semi-úmi do, apresentando duas estações perfeitamente distintas: a estação úmida e relativamente fresca, entre os meses de março-abril eagosto-setembro, ea estação quente er lati vamente seca, entre setembro-outubro e fevereiro-março. A mai or concentração das chuvas ocorre no período dos meses de abril a agosto (cerca de $68 \%$ da chuva anual), eo período mais seco vai de setembroa março (Companhia de Desenvolvimento, 1998). As temperaturas médias mensais apresentam pouca diferença durante o ano, sendo o desvio entre o mês mais quente e o mês mais frio de cerca de $5^{\circ} \mathrm{C}$ (fevereiro $28,3^{\circ} \mathrm{C}$, agosto $23,4^{\circ} \mathrm{C}$ ). Os desvios entre as temperaturas máximas médias emínimas médias mensais são mais sensíveis, chegando a valores de 7,5 a $10,7^{\circ} \mathrm{C}$. A direção predominante dos ventos na região é sudeste (SE ), segundo Agência (1988).

\section{Método utilizado}

Na margem direita do rio São F rancisco, na faixa que compreende o Perímetro I rrigado Cotinguiba/ Pindoba, for am selecionadas três áreas - seções A, B e C - onde foram instalados os ensaios para monitoramento do processo erosivo (Figura 2). Além das taxas de erosãomensal eanual, foram levantados e analisados a composição granulométrica, a coesão do material que compõe a margem, a altura do barranco, o volume de material erodido e os dados climáticos e hidrológicos da região.

Para quantificar as taxas erosivas em cada seção, foram utilizados os métodos dos pinos e das estacas. O método dos pinos, utilizado primeiramente por Wolman (1959), consiste na inserção de pinos metálicos na face da margem do rio, objetivando medir o valor da erosão através da superfície de exposição dos pinos (Figura 3). Foram utilizados pinos de aço com 1,0 m de comprimento e $6,0 \mathrm{~mm}$ de diâmetro, distribuídos em uma malha regular com espaçamento horizontal de aproximadamente $3,0 \mathrm{~m}$ e espaçamento vertical, variando de acordo com a estratificação do perfil do solo da margem. Em cada seção monitorada, foram utilizados, portanto, 12 pinos. As especificações dos pinos utilizados seguiram as recomendações de Fernandez (1990) para o uso do método dos pinos e para o estudo do processo erosivo em rios tropicais.

Após cada coleta de dados, o pino exposto pela erosão era introduzido novamente no barranco, deixando-sea vista apenas $5,0 \mathrm{~cm}$ para facilitar sua localização. O intervalo entre as col etas de dados variou de 7 a 15 dias.

A magnitude da erosão após cada medição foi calculada mediantea seguintefórmula, utilizada por Fernandez (1996):

$$
E m=\left(L_{1}-L_{0}\right) / t
$$

em que "Em" é a magnitude da erosão ( $\left.\mathrm{cm}^{\text {mês}}{ }^{-1}\right)$, " $L_{1}$ " é o comprimento do pino exposto pela erosão (cm), " $\mathrm{L}_{0}$ " é o comprimento do pino deixado exposto após cada levantamento (cm) e "t" éo tempo transcorrido em meses entre cada campanha de campo.

A erosão média calculada para cada seção monitorada, após cada medição, constituiu a resultante do somatório dos recuos registrados dividido pelo número total de pinos instalados.

O método das estacas (Hughes, 1977) consistena colocação de estacas de madeira na superfície do barranco, sendo uma primeira linha de estacas enterradas a uma distância de 3,0 me uma segunda linha a 6,0 m de distância da borda do barranco (Figura 3). Assim, o recuo é medido a partir das estacas com uma trena, ea taxa de erosãoécalculada a partir da média do recuo de cada estaca.

Neste estudo, foram utilizadas quatro estacas em cada linha, ou seja, quatro estacas a 3,0 m da borda do barranco e mais quatro estacas a 6,0 m da borda. Por ser o barranco bastante verticalizado, propício a grandes desmoronamentos, este método foi utilizado para avaliar o recuo da margem como um todo, embora normalmente tal método permita a quanti ficação do recuo da borda ou topo do barranco.

O volume aproximado de material erodido para cada seção da margem estudada foi calculado pela seguinte fórmula (Fernandez, 1990):

$$
\mathrm{Me}=\mathrm{H} . \mathrm{Er} . \mathrm{Em}
$$

em que "Me" éovolumedematerial erodido $\left(\mathrm{m}^{3} \mathrm{ano}^{-1}\right)$, "H"éa altura da margem (m), "Er"éa erosão média anual ( $\left.\mathrm{m} \mathrm{ano}^{-1}\right)$ e "E m" é a extensão lateral instrumentada $(\mathrm{m})$.

A al tura ea geometria do barranco foram obtidas pelo método de campo das perfilagens sucessivas. O método das perfilagens sucessivas (Hudson, 1981) consiste no levantamento de perfis nas margens monitoradas, com o auxílio de duas réguas portáteis colocadas, no momento da medição, uma em posição horizontal e outra em posição vertical, para ilustrar a evolução progressiva de seus perfis (Figura 4). 


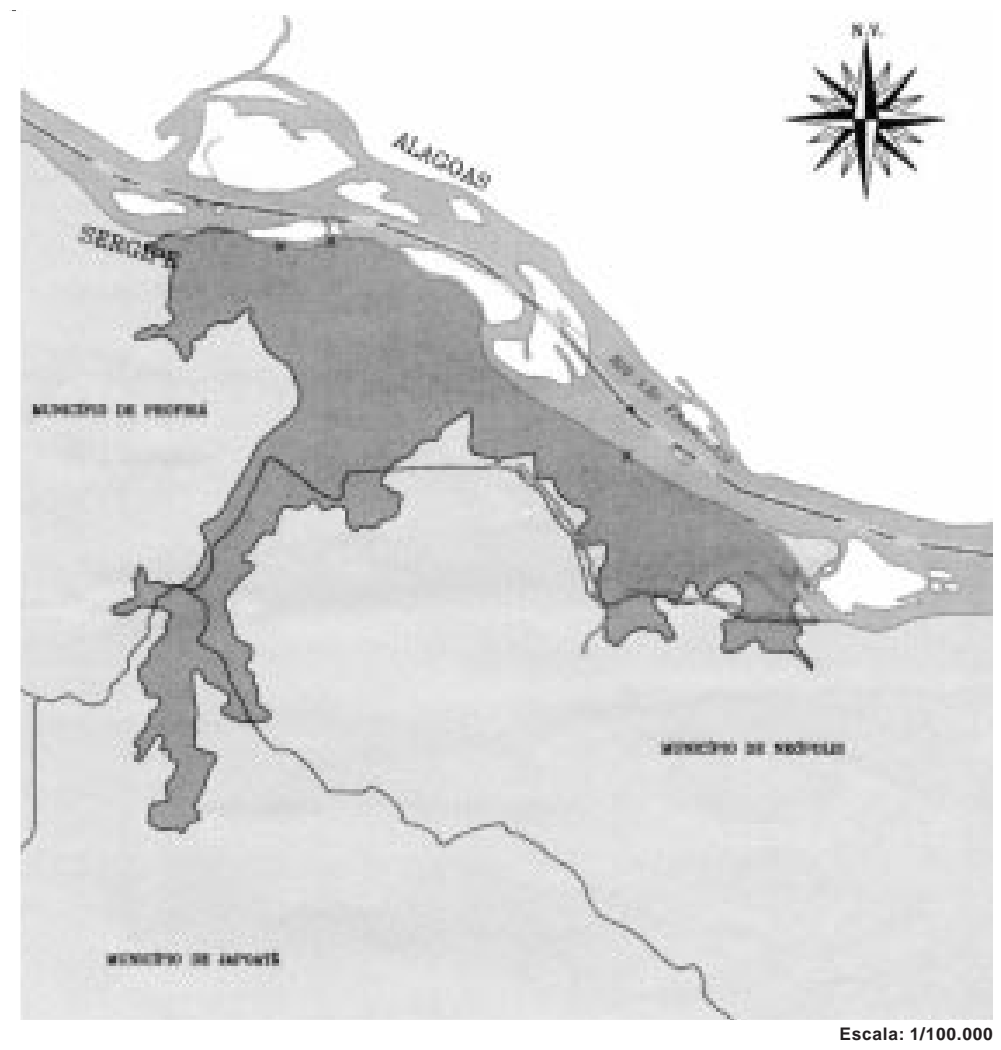

Área do perímetro irrigado

Cotinguiba/Pindoba (SE).

Rio São Francisco.

Seções selecionadas para a

montagem dos ensaios experimentais.

Figura 2. Localização das seções instrumentadas.

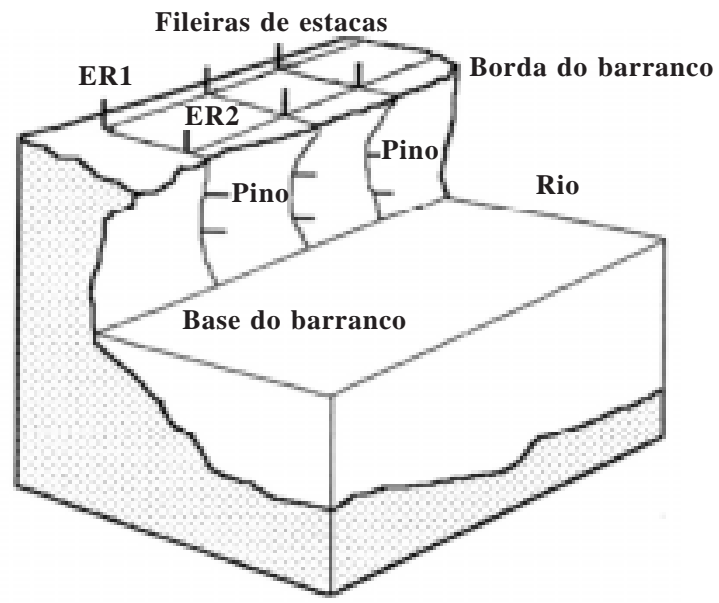

Figura 3. Representação esquemática do método dos pinos edas estacas. (Fonte: Fernandez, 1995, p.33, modificado).

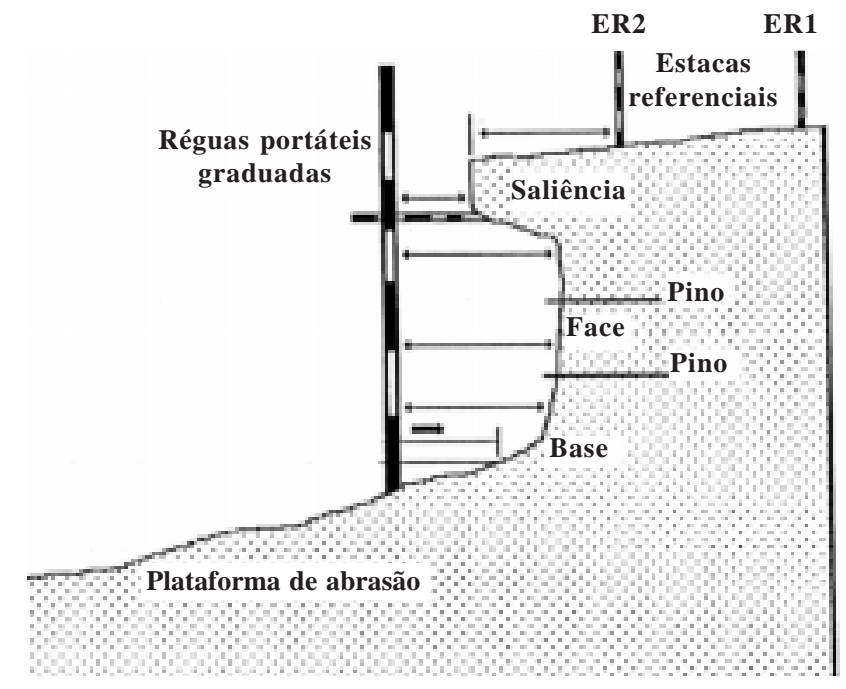

Figura 4. Representação esquemática do método das perfilagens sucessivas. (Fonte: Hudson, 1981, p.382, modificado). 
As propriedades mecânicas do barranco, tais como: a composição granul ométrica do material que compõe a margem e a coesão desse material, foram determinadas por meio do ensaio de granulometria que é uma combinação de peneiramento e sedimentação, segundo a Norma Brasileira NBR 7181 (Associação, 1984), e o ensaio de resistência ao cisal hamento direto em sol os, seguindo o procedimento do Método de Ensaio - MSL-15 (Companhia Energética, 1986).

As características hidrológicas levantadas foram a variação de cota e vazão do rio São Francisco e variações de velocidade do fluxo nas proximidade das seções instrumentadas. Os dados de cota, vazão e precipitação pluviométrica foram coletados na estação climatológica da Companhia de Desenvolvimento doVale doSão F rancisco-CODEVASF - 4åSR, localizada na área estudada.

A medição das velocidades do fluxo próximo à margem estudada foi efetuada com ouso do molinete, o qual é posto em movimento por ação da vel ocidade da água e o número de rotações dada pel o aparel ho é também dependente da velocidade da água. O molinete utilizado foi do tipo fluviométrico $\mathrm{IH}$, modelo MLN-6 com faixa de medição de 0,1 a $3,00 \mathrm{~m} \mathrm{~s}^{-1}$.

Os dados de composição granulométrica e coesão do material que compõe a margem, altura do barranco, dados climáticos e hidrológicos da área foram levantados com o objetivo fazer uma correl ação entre esses fatores e as taxas de erosão marginal .
O delineamento experimental utilizado foi em blocos casualizados com três tratamentos e quatro repetições, ou seja, cada seção - seção A, B e C constituiu-se de um bloco e cada bloco recebeu os mesmos tratamentos - métodos dos pinos, estacas e perfilagens sucessivas. As características das seções instrumentadas encontram no quadro 1.

\section{RESULTADOS E DISCUSSÃO}

\section{Quantificação da erosão marginal e volume de material erodido}

A distribuição das taxas deerosão marginal pode variar notadamente de um ponto para outro da margem, por serem variáveis as características morfológi cas e sedimentológicas do barranco e, além disso, quase sempre, a ação das ondas e a das correntes não são iguais em toda a extensão de uma margem. O ângulo de incidência da corrente na margem varia de um local para outro conforme seu traçado, ora sinuoso ora retilíneo do rio e, dessa forma, controla a magnitude dos processos erosivos. Quando as correntes batem perpendicularmente, são originados grandes desmoronamentos na margem, provocando o rápido recuo da linha de margem. Quando a corrente é paralela à margem, predominam os pequenos desmoronamentos, gerando recuos menores.

Quadro 1. Características das seções instrumentadas

\begin{tabular}{|c|c|c|c|c|c|c|}
\hline \multirow[b]{2}{*}{ Seção } & \multirow[b]{2}{*}{$\begin{array}{c}\text { Altura média do } \\
\text { barranco }\end{array}$} & \multirow[b]{2}{*}{ Camada } & \multicolumn{2}{|c|}{ Composição granulométrica } & \multirow[b]{2}{*}{ Coesão } & \multirow{2}{*}{$\begin{array}{l}\text { Vegetação da } \\
\text { superfície do } \\
\text { barranco }\end{array}$} \\
\hline & & & Silte + argila & $\begin{array}{c}\text { Areia } \\
\text { média + fina }\end{array}$ & & \\
\hline \multirow{5}{*}{ A } & \multirow[t]{2}{*}{$\mathrm{m}$} & & \multicolumn{2}{|c|}{$\mathrm{g} \mathrm{kg}^{-1}$} & $\mathrm{kPa}$ & \\
\hline & & $A$ & 159,0 & 841,0 & & \\
\hline & 5,21 & $\mathrm{C} 1$ & 877,8 & 120,5 & 12,00 & Vegetação \\
\hline & & $\mathrm{C} 2$ & 334,2 & 665,4 & & arbustiva \\
\hline & & $\mathrm{C} 3$ & 5,3 & 993,0 & & \\
\hline & & A & 901,4 & 97,1 & 15,10 & \\
\hline \multirow[t]{4}{*}{ B } & 6,36 & $\mathrm{C} 1$ & 69,1 & 930,6 & & Hortaliças \\
\hline & & $\mathrm{C} 2$ & 110,7 & 889,3 & & \\
\hline & & $\mathrm{C} 3$ & 9,7 & 953,1 & & \\
\hline & & A & 969,5 & 30,4 & 11,50 & \\
\hline \multirow[t]{3}{*}{$\mathrm{C}$} & 3,91 & $\mathrm{C} 1$ & 145,5 & 854,4 & & Pastagem \\
\hline & & $\mathrm{C} 2$ & 112,1 & 887,9 & & plantada \\
\hline & & C3 & 805,8 & 189,8 & & \\
\hline
\end{tabular}


Na área estudada, as taxas de erosão marginal acumulada, no período de abrangência da col eta de dados, foram de $8,30 \mathrm{~m}$, na seção $A ; 47,30 \mathrm{~m}$, na seção B, e 4,45 m, na seção C (Quadro 2).

Os dados mostram queas maiores taxas de recuo da margem estão relacionadas com a presença de material arenoso, e conseqüentemente, sem coesão na base do barranco (Quadro 1), local ondeas ondas provocavam o solapamento dessa base, ocasionando o desmoronamento do material da margem do rio.

A partir das observações de campo, constatou-se que as seções estudadas apresentavam um perfil verticalizado, variando apenas a altura e as percentagens deareia, silte eargila do material que caracterizava o barranco. Analisando os dados apresentados no quadro 2, observou-se quea seção B apresentou maior taxa de erosão anual justificada também pela sua maior altura média do barranco (Quadro 1). Diferentemente, a seção $C$ foi a que apresentou menores taxas de erosão, sendo esta a seção de menor altura do barranco. Essa seção apresentou as menores percentagens de material arenoso e maiores percentagens de arglia e silte na composição das camadas da base do barranco (Quadro 1), dificultando a erosão marginal.

Quadro 2. Taxa de erosão e volume de material erodido

\begin{tabular}{ccc}
\hline Seção & Taxa de erosão & $\begin{array}{c}\text { Volume de material } \\
\text { erodido }\end{array}$ \\
\hline & $\mathrm{m} \mathrm{ano}^{-1}$ & $\mathrm{~m}^{3}$ \\
$\mathrm{~A}$ & 8,30 & 518,91 \\
$\mathrm{~B}$ & 47,30 & $36.099,94$ \\
$\mathrm{C}$ & 4,45 & 208,79 \\
\hline
\end{tabular}

O volume de material erodido em cada seção monitorada foi de 518,91 $\mathrm{m}^{3}$ na seçãoA, 36099,94 m³ na seção B e208,79 m³ na seção C (Quadro 2). Para calcular o volume, foram usados a altura média do barranco e o valor de $12 \mathrm{~m}$ de extensão lateral da área monitorada.

\section{Distribuição temporal das taxas de erosão}

A erosão marginal tem uma importante distribuição temporal. Ela não é contínua e está vinculada às magnitudes dos eventos climáticos, principal mentea intensidade do vento e dos eventos hidrológicos, como a variação da vazão, a variação da cota e a velocidade do fluxo. I sso, associado às características do barranco em cada ponto, fez com que as taxas erosivas fossem maiores em determinados meses do ano (Figura 5 e Quadro 3).

\section{Fatores hidrológicos e climáticos}

Com relação à vazão do rio São Francisco, observou-se uma variação discreta da vazão durante os meses de estudo; todavia, notou-se um aumento da vazão nos meses de fevereiro, outubro, novembro e dezembro de 1999 e janeiro de 2000 (Quadro 3), por ser a vazão do rio São Francisco controlada por barragens localizadas ao longo do seu leito, principalmente pelas barragens de Sobradinho e Xingó. Os meses compreendidos entre outubro e fevereiro correspondem ao período do ano de maior pluviosidade no alto e médio curso do rio São Francisco, onde ocorre a maior contribuição de descarga do seus afluentes mais importantes. $O$ período de maior pluviosidade no Baixo São Francisco - de abril a agosto - não revel ou aumento da vazão do rio no trecho estudado, ao contrário, coincidiu com os meses de menor vazão média.

A velocidade do fluxo nas proximidades da margem estudada foi de $0,543 \mathrm{~m} \mathrm{~s}^{-1}$ a $5,0 \mathrm{~m}$ de

Quadro 3. Dados hidrológicos e climáticos da área de estudo, no período de fevereiro de 1999 a janei ro de 2000

\begin{tabular}{lcccc}
\hline Mês & Cota média & Amplitude da cota & Vazão média & $\begin{array}{c}\text { Velocidade média } \\
\text { do vento }\end{array}$ \\
& $\mathrm{m}$ & $\mathrm{m}$ (cotamáx - cota $\min )$ & $\mathrm{m}^{3} \mathrm{~s}^{-1}$ & $\mathrm{~m} \mathrm{~s}^{-1}$ \\
Fevereiro & 2,38 & 0,46 & 1897 & 1,814 \\
Março & 2,20 & 0,50 & 1702 & 1,553 \\
Abril & 2,29 & 0,58 & 1799 & 1,384 \\
Maio & 2,29 & 0,56 & 1757 & 0,969 \\
J unho & 2,27 & 0,46 & 1765 & 0,830 \\
Julho & 2,24 & 0,37 & 1736 & 1,296 \\
Agosto & 2,29 & 0,38 & 1725 & 1,315 \\
Setembro & 2,27 & 0,24 & 1789 & 1,186 \\
Outubro & 2,38 & 0,38 & 2032 & 1,385 \\
Novembro & 2,43 & 0,52 & 2229 & 1,488 \\
Dezembro & 2,63 & 0,60 & 2022 & 1,610 \\
J aneiro & 2,47 & 0,35 & & 1,465 \\
\hline
\end{tabular}




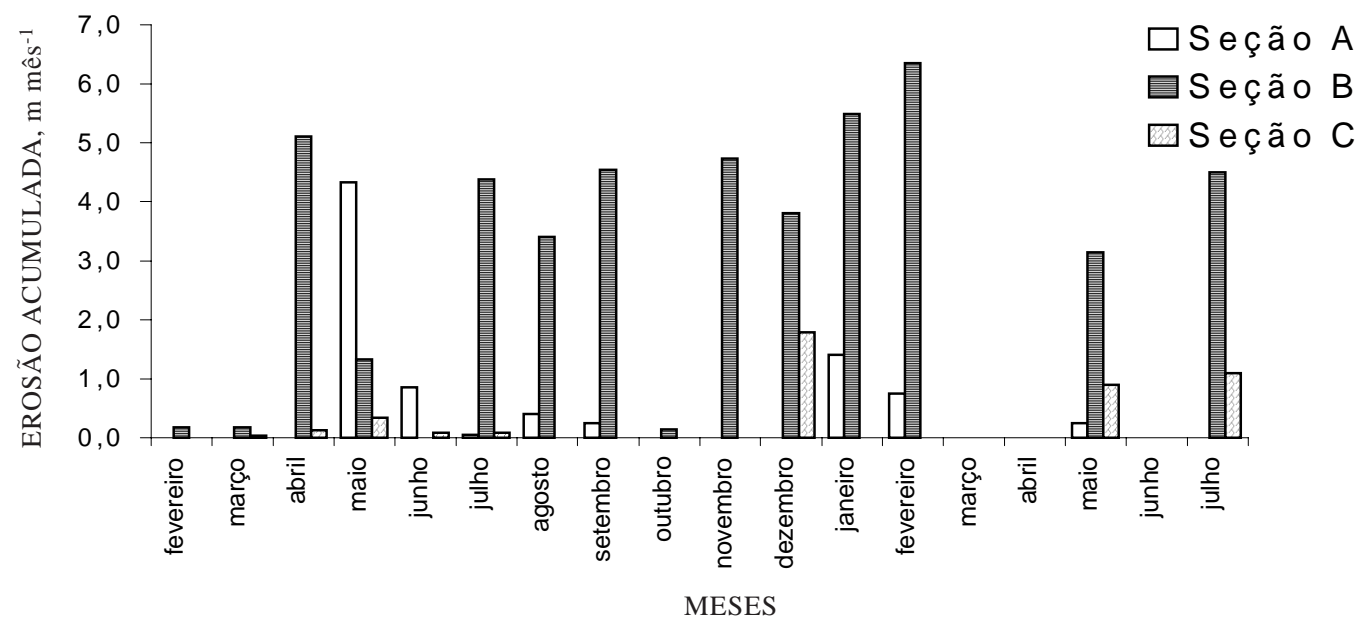

Figura 5. Taxas de erosão mensal nas seções monitoradas.

distância da margem, sendo essa vel ocidade superior à velocidade mínima de arraste de partículas com diâmetro de até $0,42 \mathrm{~mm}$ (Gilbert citado por Christofoletti, 1981) - correspondente ao material arenoso queéoquecompõea mai or parteda margem estudada, criando, assim, condições favoráveis que facilitam a retirada do material da base do barranco, tornando-o instável.

Associado à velocidade do fluxo próximo à margem, a direção predominante do vento coincidindo com o senti do da corrente do rio-sudeste (SE) pode-se tornar importante fator na formação de ondas que provocam o solapamento progressivo dos barrancos e conseqüente desmoronamento da suas partes superiores.

\section{CONCLUSÕES}

1. A presença de material arenoso e, conseqüentemente, sem coesão na base do barranco, onde a ação de ondas provocavam o solapamento dessa base ocasionando o desmoronamento do material da margem do rio, constituiu rel evantefator de importância no que se refere às el evadas taxas de erosão nas seções estudadas.

2. A altura do barranco foi um fator de grande importância na avaliação das taxas erosivas, os barrancos com as maiores alturas mostraram-se instáveis mais facilmente com a retirada do material de base pelo solapamento.

3. As taxas erosivas, mensais e anual, também foram influenciadas pela ação associada das variáveis velocidade e direção predominante do vento, amplitude mensal da cota, cota máxima mensal e velocidade do fluxo próxima à margem.

\section{LITE RATURA CITADA}

AGÊNCIA de Meteorologia em Salvador/BA. Direção do vento e vel ocidade na estação climatológica de Propriá/SE - período de 1978 a 1987. 1988.

ASSOCIAÇÃO BRASI LEIRA DE NORMASTÉCNICAS - ABNT. Solo - análise granulométrica (NBR 7181). Rio de J aneiro, 1984. 13p.

CASADO, A.P.B. Estudo do processo erosivo na margem direita do rio São Francisco (perímetro irrigado Cotinguiba/ Pindoba - Baixo São Francisco Sergipano). Aracaju, Universidade Federal de Sergipe, 2000. 108p. (Tese de Mestrado)

COMPANHIA ENERGÉTICA DE SÃO PAULO - CESP. Ensaio de cisalhamento direto em solos (Método de Ensaio MSL15). Il ha Solteira, 1986. 25p.

COMPANHIA DE DESENVOLVIMENTO DO VALE DO SÃO FRANCISCO - CODEVASF. Ficha técnica do perímetro Cotinguiba/Pindoba. Aracaju, 1998. 13p.

CHRISTOFOLETTI, A. Geomorfologia fluvial - o canal fluvial. São Paulo, Edgard Blucher, 1981. 313p. v.1.

FERNANDEZ, O.V.Q. Mudanças no canal fluvial do rio Paraná e processos de erosão nas margens: região de Porto Rico, PR. Rio Claro, Universidade Estadual de São Paulo, 1990. 86p. (Tese de Mestrado)

FERNANDEZ, O.V.Q. Erosão marginal no lago da UHE I taipu (PR). Rio Claro, UniversidadeEstadual deSão Paulo, 1995. 107p. (Tese de Doutorado)

FERNANDEZ, O.V.Q. O método dos pinos na quantificação da erosão marginal em rios reservatórios. In: SIMPÓSIO NACIONAL DE GEOMORFOLOGIA, 1., 1996, Uberlândia. Anais. Uberlândia, Universidade Federal de Uberlândia, 1996. p.160-163.

FONTES, A.L. Estudo integrado das sub-bacias do Baixo São Francisco Sergipano: região dos tabuleiros costeiros e pediplano sertanejo - geomorfologia. Aracaju, Companhia de Desenvolvimento do Vale do São Francisco/Núcleo de Estudos do Semi-Árido, 1999. 140p.(no Prelo) 
HOLANDA, F.S.R. Estudo integrado do vale do São Francisco Sergipano: região de tabuleiros costeiros e pediplano sertanejo - pedologia. Aracaju, Companhia de Desenvolvimento do Vale do São Francisco/Núcleo de Estudos do Semi-Árido, 2000. 137p.

HOOKE, J.M. An analalysis of the processes of river bank erosion. J. Hydrol., 42:39-62, 1979.

HOOKE, J.M. Magnitude and distribution of rates river bank erosion. Earth Sur. Proc., 5:143-157, 1980.

HUDSON, N. A field technique to directly measure river bank erosion. Can. J. Earth Sci., 19:381-383, 1981.
HUGHES, D.J. Rates of erosion on meanderarcs. In: RIVER channel changes. J ohn Wiley \& Sons, 1977. p.193-205.

OLIVEIRA, J.B.; ACOMINE,P.K.T. \& CAMARGO, M.N. Classes gerais de solos do Brasil. 2.ed. J aboticabal, Fundação Nacional de Pesquisa, 1992. 201p.

ROSS, J .L.S. O registro cartográfico dos fatos geomorfológicos e a questão da taxonomia do relevo. R. Dep. Geografia, 6:17-30, 1992.

THORNE, C.R. \& TOVEY, N.K. Stability of composite river banks. Earh Sur. Proc. Landforms, 6:469-484, 1981.

WOLMAN, M.G. Factors influencing erosion of a cohesive river bank. Am. J. Sci., 257:204-216, 1959. 
A.P.B. CASADO et al.

R. Bras. Ci. Solo, 26:231-239, 2002 